\title{
Automated Quantitation of Spinal CSF Volume and Measurement of Craniospinal CSF Redistribution following Lumbar Withdrawal in Idiopathic Intracranial Hypertension
}

\author{
(D) N. Alperin, (D)A.M. Bagci, (D) S.H. Lee, and B. B.L. Lam
}

\begin{abstract}
BACKGROUND AND PURPOSE: Automated methods for quantitation of tissue and CSF volumes by MR imaging are available for the cranial but not the spinal compartment. We developed an iterative method for delineation of the spinal CSF spaces for automated measurements of CSF and cord volumes and applied it to study craniospinal CSF redistribution following lumbar withdrawal in patients with idiopathic intracranial hypertension.
\end{abstract}

MATERIALS AND METHODS: MR imaging data were obtained from 2 healthy subjects and 8 patients with idiopathic intracranial hypertension who were scanned before, immediately after, and 2 weeks after diagnostic lumbar puncture. Imaging included T7-weighted and T2-weighted sequences of the brain and T2-weighted scans of the spine. Repeat scans in 4 subjects were used to assess measurement reproducibility. Whole CNS CSF volumes measured prior to and following lumbar puncture were compared with the withdrawn amounts of CSF.

RESULTS: CSF and cord volume measurements were highly reproducible with mean variabilities of $-0.7 \% \pm 1.4 \%$ and $-0.7 \% \pm 1.0 \%$, respectively. Mean spinal CSF volume was $77.5 \pm 8.4 \mathrm{~mL}$. The imaging-based pre- to post-CSF volume differences were consistently smaller and strongly correlated with the amounts removed $(R=0.86, P=.006)$, primarily from the lumbosacral region. These differences are explained by net CSF formation of $0.41 \pm 0.18 \mathrm{~mL} / \mathrm{min}$ between withdrawal and imaging.

CONCLUSIONS: Automated measurements of the craniospinal CSF redistribution following lumbar withdrawal in idiopathic intracranial hypertension reveal that the drop in intracranial pressure following lumbar puncture is primarily related to the increase in spinal compliance and not cranial compliance due to the reduced spinal CSF volume and the nearly unchanged cranial CSF volume.

ABBREVIATIONS: $॥ \mathrm{H}$ = idiopathic intracranial hypertension; $\mathrm{LP}=$ lumbar puncture

$\mathbf{T}$ he total amount of CSF and its craniospinal distribution are important for understanding of CSF-related brain and spinal cord disorders and CSF physiology in general. Changes in CSF circulation or distribution between the cranium and spinal canal or both have been observed in several neurologic disorders, including Alzheimer disease, ${ }^{1}$ idiopathic normal pressure hydrocephalus, ${ }^{2}$ idiopathic intracranial hypertension (IIH), ${ }^{3}$ and even during pregnancy. ${ }^{4} \mathrm{~A}$ change in body posture also affects the cra-

Received November 25, 2015; accepted after revision April 19, 2016.

From the Department of Radiology (N.A., A.M.B., S.H.L.), University of Miami, Miami, Florida; and Bascom Palmer Eye Institute (B.L.L.), University of Miami, Miami, Florida. This study was funded by a seed grant from the North American Neuro-Ophthalmology Society.

Paper previously presented in part at: Annual Meeting of the American Society of Neuroradiology and the Foundation of the ASNR Symposium, May 21-26, 2016; Washington DC.

Please address correspondence to Noam Alperin, PhD, Department of Radiology, University of Miami, Professional Arts Center, Suite 713, 1150 NW 14th St, Miami,

FL 33136; e-mail: NAlperin@med.miami.edu

http://dx.doi.org/10.3174/ajnr.A4837 niospinal CSF distribution, with a shift from the cranium to the spinal canal contributing to the lower intracranial pressure observed in the upright-versus-supine postures. ${ }^{5}$ CSF volume in the spinal canal is also influenced by abdominal compression and hyperventilation. ${ }^{6}$ In addition, the amount of CSF in the thecal sac has been shown to influence the effectiveness of spinal anesthesia. ${ }^{7}$ Not only the spinal CSF volume but also the spinal cord volume is of clinical relevance, especially for cord atrophy progression such as in multiple sclerosis. ${ }^{8}$

MR imaging-based automated methods of quantitation of brain tissues and intracranial CSF volumes ${ }^{9,10}$ have considerably advanced the quantitative-based diagnostic capability of many neurologic problems, yet comparable methods for the spinal cord and the spinal CSF volumes are not widely available. Measurement of the spinal CSF volume in MR imaging is challenging because of the overall smaller volumes compared with the brain and cranial volumes and due to the length of the spinal canal, which necessitates the use of multiple overlapping acquisitions with potentially varying image nonuniformity. 


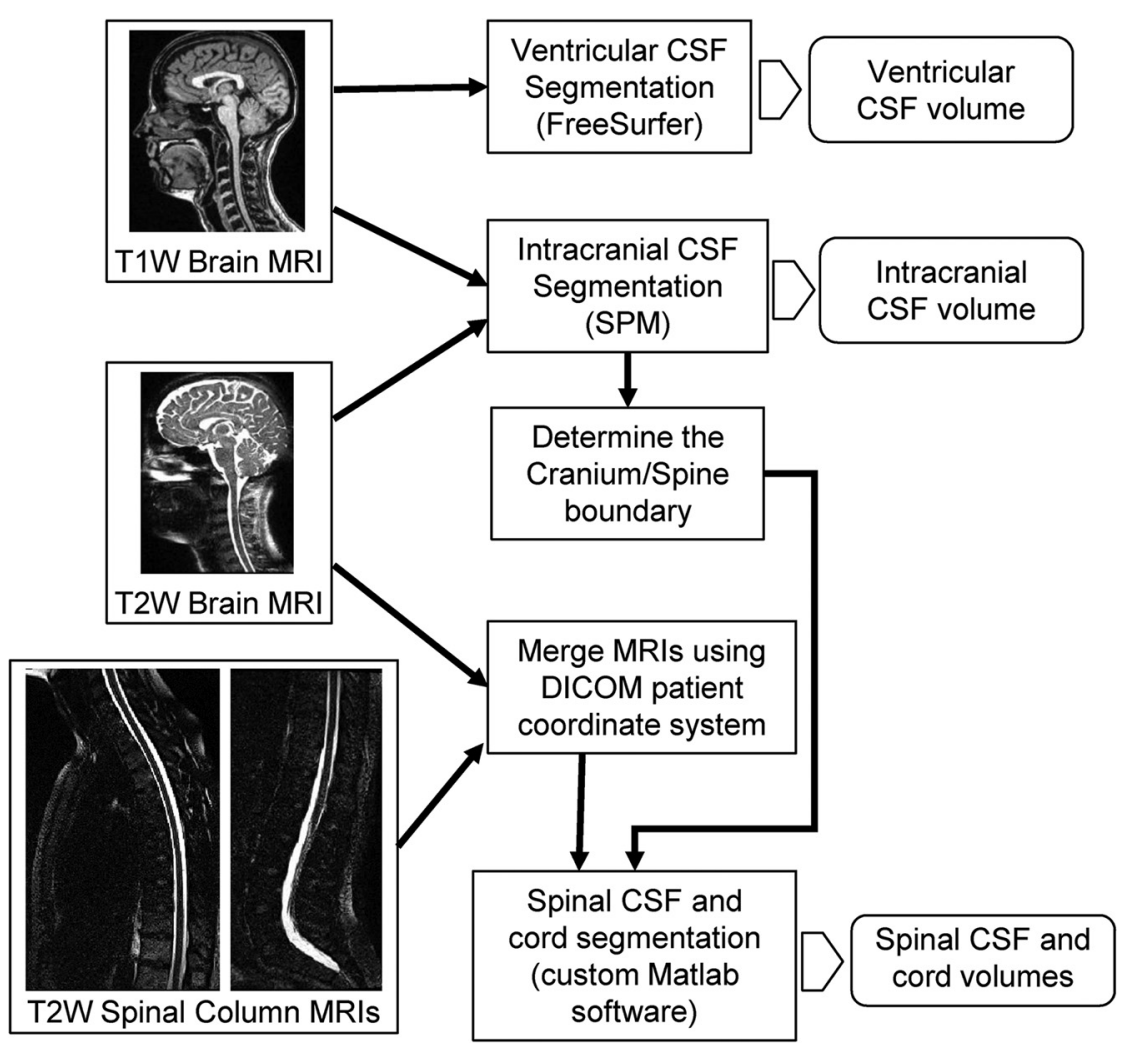

FIG 1. Flow chart of the CSF segmentation method. T1- and T2-weighted brain images are used to obtain the ventricular and intracranial CSF volumes by using publicly available software packages. Spinal CSF and cord volumes are obtained using the 3 T2-weighted scans with a custom-developed software.

Previous studies on dose response in epidural anesthesia focused on measurements of the CSF volumes in the low thoracic and lumbosacral regions. ${ }^{4,6,11}$ The CSF volume in the whole spinal canal was reported only in a small number of studies that were constrained by limited image resolution and manual delineation of the CSF space. ${ }^{11,12}$ A recent advancement toward automated spinal CSF volume measurements is the development of a method that uses thresholding and voxel connectivity. ${ }^{13}$ Recent effort in the assessment of spinal cord atrophy in multiple sclerosis includes semiautomated approaches for the measurement of the cord cross-sectional areas in both cervical and thoracic regions. ${ }^{14}$

This article describes an iterative method of delineating the CSF spaces and the spinal cord throughout the spinal canal. Measurement reproducibility was assessed from repeat measurements in the same subjects. The method efficacy is demonstrated by its application to studying the impact of CSF withdrawal by lumbar puncture (LP) on the craniospinal CSF redistribution in IIH. Only limited information on CSF redistribution following withdrawal is available, even though this is a commonly used diagnostic procedure in CSF-related disorders.

\section{MATERIALS AND METHODS \\ Study Participants}

Data from a cohort of 8 overweight women (age $29 \pm 6$ years; range, 19-37 years; mean body mass index: $34 \pm 7 \mathrm{~kg} / \mathrm{m}^{2}$; range, $26-43 \mathrm{~kg} / \mathrm{m}^{2}$ ) who underwent lumbar puncture for the suspected diagnosis of IIH and from 2 healthy female subjects (ages, 27 and 31 years; body mass index, 20 and $27 \mathrm{~kg} / \mathrm{m}^{2}$ ) were used in the evaluation of the method. Written informed consent was obtained on enrollment, and the study was approved by the institutional review board. Each of the 8 patients underwent $3 \mathrm{MR}$ imaging scans, immediately before and after $(22 \pm 7$ minutes) diagnostic lumbar puncture and a follow-up scan $15 \pm 5$ days (range, 8-23 days) after lumbar puncture. In 4 subjects, MR imaging was repeated to assess measurement reproducibility and as a control for the subjects who underwent CSF withdrawal between scans.

Lumbar punctures were performed as a routine clinical procedure by a neurologist by using a 20 -ga needle. The procedure was performed in a room adjacent to the MR imaging suite, with the patient in a lateral recumbent position. The CSF drainage was continued until 15-20 mL of fluid was collected or until the flow stopped. Following LP, all patients reported improvement of symptoms with no relapse at the follow-up MR imaging, and none reported post-LP headache.

\section{MR Imaging Acquisition}

MR imaging studies were performed by with a $1.5 \mathrm{~T}$ scanner (Symphony; Siemens, Erlangen, Germany) and the scanner-integrated Tim head, neck, and spine coils. Volumetric assessment of the cranial compartments was obtained from 3D T1-weighted and T2-weighted MPRAGE and sampling perfection with application-optimized contrasts by using different flip angle evolution (SPACE; Siemens) sequences, respectively. Imaging parameters of the T1-weighted scans included TR/TE/TI of 2200/ $2.37 / 1000 \mathrm{~ms}$, flip angle of $8^{\circ}, \mathrm{FOV}$ of $25.6 \times 22.4 \mathrm{~cm}, 1-\mathrm{mm}$ isotropic resolution, and scan duration of 4 minutes and 15 seconds. Imaging parameters for the T2-weighted scan included the following: TR/TE of $1800 / 193 \mathrm{~ms}$, flip angle of $150^{\circ}$, FOV of $25.0 \times 23.8 \mathrm{~cm}, 1-\mathrm{mm}$ isotropic resolution with scan duration of 3 minutes and 15 seconds. The spinal column was imaged by using 2 separate 3D T2-weighted scans with approximately $10 \%$ overlap in coverage with TR/TE of 1500/245 ms; flip angle of $120^{\circ}$; FOV of $30 \times 30 \mathrm{~cm}$; acquisition matrix of $330 \times 330$ with no zero-filling, yielding $0.9-\mathrm{mm}$ isotropic voxels; and scan duration of 5 minutes each. Images were acquired in the sagittal orientation.

\section{Segmentation of the Craniospinal CSF Volume}

The flowchart of the procedure for segmentation of the entire spinal canal CSF and spinal cord is shown in Fig 1. The ventricular and intracranial CSF volumes were quantified by using the publicly available FreeSurfer (http://surfer.nmr.mgh. harvard.edu) and SPM8 software (http://www.fil.ion.ucl.ac.uk/ spm/) packages, ${ }^{9,10}$ respectively. The method for the segmenta- 
tion of the spinal CSF and cord volumes was implemented in Matlab, Version 2015a (MathWorks, Natick, Massachusetts).

\section{Segmentation of Intracranial CSF Volume}

Delineation of the ventricles was obtained from T1-weighted sequences with the FreeSurfer software, ${ }^{9}$ which uses an atlas-based method as prior information in a Bayesian parameter estimation framework to identify several brain regions, including the ventricular system.

Intracranial CSF was obtained with the New Segment tool in SPM8 software, which allows multitechnique segmentation by using both T1-weighted and T2-weighted images and incorporates a priori spatial information by using tissue probability maps. ${ }^{10}$ Regions outside the cranium with image intensity like CSF (eg, vitreous humor) were removed from the final segmentation by using a skull mask generated by the FSL Brain Extraction Tool (http://fsl.fmrib.ox.ac.uk/fsl/fslwiki/BET). ${ }^{15}$ The coordinates of the most inferior axial section containing CSF segmentation are automatically determined and used to initialize the automated segmentation of the spinal CSF.

\section{Segmentation of Spinal CSF and Spinal Cord}

Before spinal canal CSF segmentation, T2-weighted scans of the cranium and cervical-thoracic and thoracic-lumbar regions were merged on the basis of the patient coordinates. The CSF and cord segmentation was initialized at the coordinates of the most inferior voxels of CSF from intracranial segmentation. The segmentation was performed automatically on axial reformatted sections, superior-to-inferior. A Laplacian of Gaussian filter $(\sigma=1.2 \mathrm{~mm}$, filter size $=9 \times 9 \mathrm{~mm}$ ) was then applied to enhance the CSF/cord edge pixels. The resulting edge-enhanced image is then convolved with 2D-matched filters to detect the size and the position of the cord. The filter kernels, optimized to detect elliptic structures, varied from 5- to 15-mm diameter and were elliptic with varying aspect ratios from 1:1 to 1:2. The shape, location, and size of the cord are determined on the basis of the filter kernel with the highest frequency response. This initial boundary is further refined by moving the boundary pixels to the zero-crossings on the edgeenhanced image within a $1-\mathrm{mm}$ range. The spinal CSF is segmented by using an active contour algorithm ${ }^{16}$ on the edge-enhanced image. Segmentation of the consecutive sections is separated into 2 different regions: the cervical and thoracic regions that include a cord and a lumbar region that does not include a cord. The location of the center voxel of the CSF segmentation serves as the initialization point for segmentation on the next axial slide. The volume of the CSF in the spinal canal is then obtained by summation of the voxels identified as spinal canal CSF. Additionally, the cross-sectional area of the CSF spaces along the spinal column was determined to assess the redistribution of CSF along the spinal canal following CSF withdrawal.

\section{Assessment of CSF Volumes before and after Lumbar Puncture}

The cranial and spinal CSF volumes measured by MR imaging before the lumbar puncture scan were compared with values measured after lumbar puncture and follow-up scans. The locations along the space where there was a change in the CSF volume were identified by plotting the mean difference between pre- and postlumbar puncture cross-sectional areas with respect to the distance from the foramen magnum. The amount of CSF collected during lumbar puncture was compared with differences in the CSF volume measured by MR imaging pre- to post and pre- to follow-up scans. The effective CSF formation rate was estimated to account for CSF formed between the lumbar puncture and the MR imaging acquisition.

\section{Measurement Reproducibility and Accuracy}

Measurement reproducibility of spinal canal CSF and cord volume was assessed by calculating the mean and SD of the relative and absolute differences between the 2 repeat scans. Calibration of the volume measurement was assessed by using a CSF canallike water phantom built by using a $42-\mathrm{cm}$ rod with a diameter of $1.2 \mathrm{~cm}$ inserted into a 56-cm-long hollow tube with an inner diameter of $2.6 \mathrm{~cm}$. The phantom was filled with $252.5 \mathrm{~mL}$ of water, as measured with a graduated cylinder. The phantom was scanned by using the same imaging parameters as those used for subjects.

\section{Statistical Analysis}

The within-subject differences in CSF and cord volumes were tested for statistical significance by using paired $t$ tests following testing for normality by using the Shapiro-Wilk test. Associations between pre- to post-lumbar puncture differences in CSF volume and the amounts withdrawn were tested by calculating the Pearson correlation coefficient. A $P$ value $<.05$ was considered significant. The intersubject variability for CSF volume of each compartment was calculated as the ratio of its mean to SD. The repeatability coefficient (ie, the maximum difference that is expected to occur between repeat measurements) was calculated as 1.96 times the SD of the differences between the repeat measurements. All results are expressed as mean \pm SD. All statistical analyses were performed by using MedCalc for Windows, Version 15.8 (MedCalc Software, Mariakerke, Belgium).

\section{RESULTS}

The mean and SD of the relative and absolute differences in CSF volume measurements between repeat scans were $-0.5 \pm 1.0$ and $0.8 \pm 0.7 \mathrm{~mL}$, respectively, which correspond to a percentage difference of $-0.7 \pm 1.4 \%$ and $1.1 \pm 0.9 \%$, respectively, and a repeatability coefficient of $1.9 \mathrm{~mL}$. The mean and SD and percentage differences in cord volume were $0.1 \pm 0.2 \mathrm{~mL}$ and $-0.7 \pm$ $1.0 \%$, respectively, with a repeatability coefficient of $0.4 \mathrm{~mL}$. Absolute volume measurements obtained with the spine phantom demonstrated good accuracy with a small error of only $0.4 \%$.

An example of whole craniospinal CSF segmentation is shown in Fig 2. Sample segmented spinal CSF spaces and cord segmentations in regions with and without cord are shown in Fig 3. Prelumbar puncture cranial CSF (intra- and extraventricular), spinal CSF, and cord volumes measured in each of the 8 patients are listed in Table 1. The mean total craniospinal CSF volume measured in the patient cohort was $258 \pm 35.6 \mathrm{~mL}$, with $164 \pm 32 \mathrm{~mL}$ in the extraventricular (sulcal) cranial CSF spaces, $16.2 \pm 6.0 \mathrm{~mL}$ in the ventricles, and $77.5 \pm 8.4 \mathrm{~mL}$ in the spinal canal. CSF volumes in the different compartments varied among individuals, 


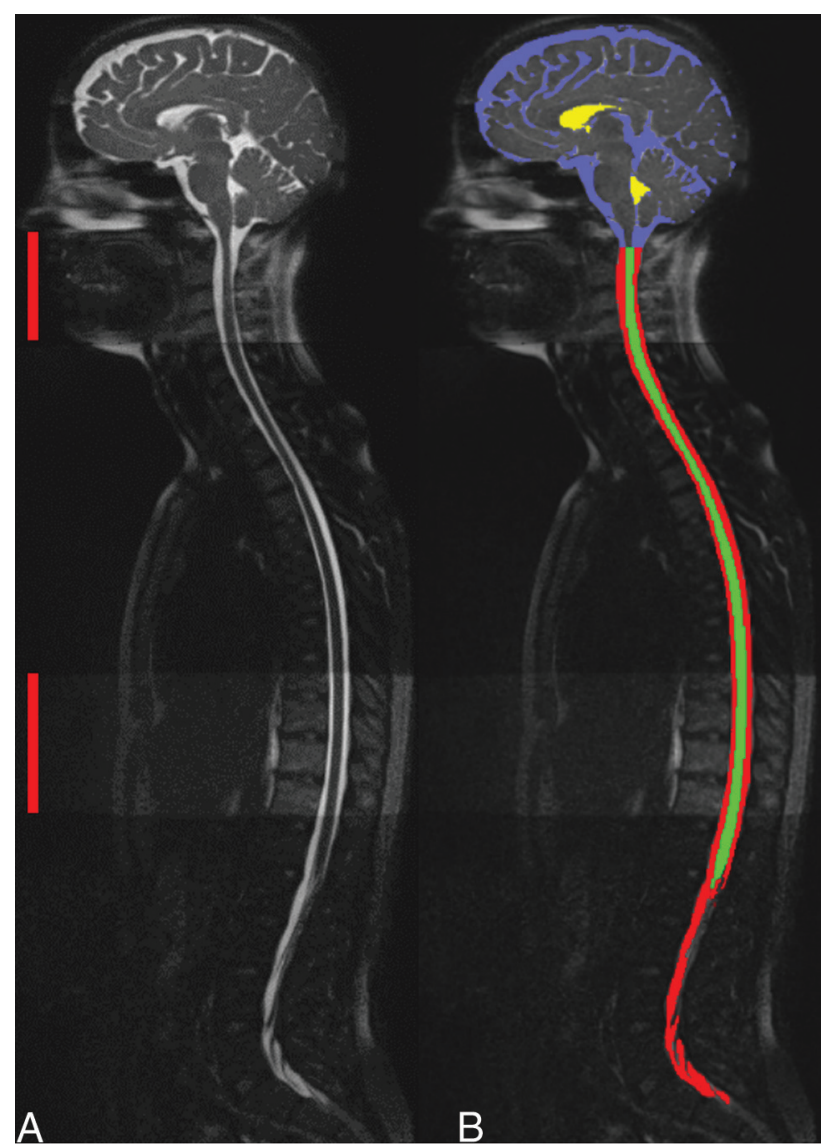

FIG 2. A mid-sagittal image demonstrating complete coverage of the CNS generated by merging 3 separate acquisitions $(A)$ with overlapping coverage indicated by red bars on the left. $B$, Segmentation of cranial (blue), ventricular (yellow), and spinal (red) CSF and cord (green).

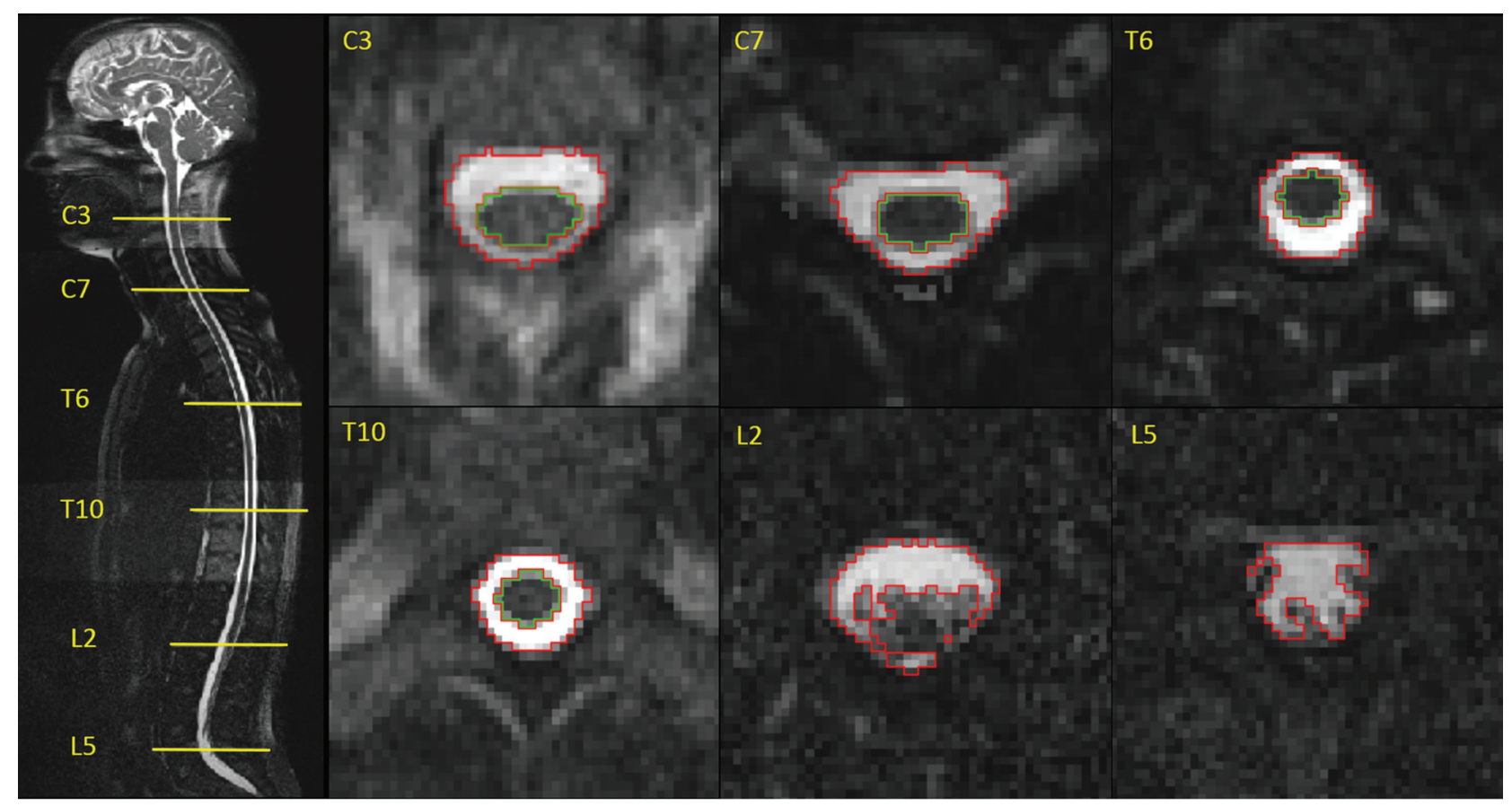

with the largest variability found in the ventricular CSF volume (37\%) and smallest variability in the spinal CSF volume (11\%). The mean cord volume was $21.0 \pm 2.0 \mathrm{~mL}$, with a relatively small interindividual variability of $10 \%$.

The differences between the pre- and post-LP measurements of intracranial pressure and CSF volumes at the various craniospinal compartments for each of the 8 patients are listed in Table 2. Following lumbar puncture, closing pressure was significantly lower with a mean pressure change of $-17 \pm 8.6 \mathrm{~cm} \mathrm{H}_{2} \mathrm{O}(P=$ $.002)$, and the measured total CSF volume was significantly reduced, as expected, by an average of $-7.5 \pm 2.9 \mathrm{~mL}(P=.0002)$. Most of the change in CSF volume occurred in the spinal canal, with a mean value of $-6.7 \pm 3.2 \mathrm{~mL}(P=.0007)$. A plot of the mean CSF cross-sectional area as a function of the distance from the foramen magnum obtained before and after lumbar puncture is shown in Fig $4 A$. The difference between these 2 plots is shown in Fig $4 B$, demonstrating that the reduction is primarily localized at the lumbosacral region. The spinal CSF volume measured at the 2-week post-LP-scan follow-up was still significantly lower than that of the pre-lumbar puncture by an average of $1.9 \pm 1.7 \mathrm{~mL}$ $(P=.016)$. No significant differences were observed in the other compartments. As expected, no significant differences were measured in the cord volume between scans. Mean differences between the pre- and post-LP and the pre- and 2-week follow-up scans were $-0.3 \pm 0.5$ and $+0.1 \pm 0.5 \mathrm{~mL}$, respectively.

The difference in measured CSF volume in the spinal canal between the pre- and post-LP scans and the 2-week follow-up scan were linearly correlated with the withdrawn amount of CSF with strong correlation coefficients of $R=0.86, P=.006$, and $R=$ $0.75, P=.03$, respectively. The scatterplots for these relationships are shown in Fig 5. The measured pre- to post-LP difference of $7.5 \pm 2.9 \mathrm{~mL}$ was lower than the withdrawn amount of $15.8 \pm 3.9$ $\mathrm{mL}$. Assuming that this difference is, in part, due to net CSF

FIG 3. Sample CSF (red outline) and cord (green) segmentations along the spinal column at the level of $C 3, C 7, T 6, T 10, L 2$, and L5 vertebrae. 
Table 1: Compartmental CSF volumes measured before lumbar puncture in patients

\begin{tabular}{|c|c|c|c|c|c|c|c|c|}
\hline & Age (yr) & BMI & $\begin{array}{l}\text { Opening } \\
\text { Pressure } \\
\left(\mathrm{cm} \mathrm{H}_{2} \mathrm{O}\right)\end{array}$ & $\begin{array}{l}\text { EVC CSF } \\
\text { Vol (mL) }\end{array}$ & $\begin{array}{l}\text { Ventricular } \\
\text { CSF Vol (mL) }\end{array}$ & $\begin{array}{l}\text { SC CSF } \\
\text { Vol (mL) }\end{array}$ & $\begin{array}{l}\text { Total CSF } \\
\text { Vol (mL) }\end{array}$ & $\begin{array}{c}\text { Cord } \\
\text { Vol }(\mathrm{mL})\end{array}$ \\
\hline \multicolumn{9}{|l|}{ Subject No. } \\
\hline 1 & 28 & 34 & 39 & 164 & 18.9 & 86.7 & 269 & 20.8 \\
\hline 2 & 37 & 33 & 45 & 169 & 15.6 & 83.1 & 268 & 23.5 \\
\hline 3 & 19 & 26 & 17 & 157 & 16.4 & 76.8 & 250 & 21.9 \\
\hline 4 & 33 & 27 & 29 & 171 & 11.6 & 77.3 & 260 & 20.7 \\
\hline 5 & 28 & 43 & 34 & 213 & 12.8 & 67.6 & 293 & 19.9 \\
\hline 6 & 32 & 40 & 34 & 166 & 28.9 & 89.8 & 285 & 23.9 \\
\hline 7 & 30 & 41 & 25 & 176 & 15.8 & 68.9 & 261 & 18.8 \\
\hline 8 & 22 & 30 & 40 & 98 & 9.2 & 69.9 & 177 & 18.6 \\
\hline Mean & $29 \pm 6$ & $34 \pm 6.7$ & $33 \pm 9.1$ & $164 \pm 31.8$ & $16.2 \pm 6.0$ & $77.5 \pm 8.4$ & $258 \pm 35.6$ & $21.0 \pm 2.0$ \\
\hline Variability (SD/Mean) & & & & $19 \%$ & $37 \%$ & $11 \%$ & $14 \%$ & $10 \%$ \\
\hline
\end{tabular}

Note:-BMI indicates body mass index; EVC, extraventricular cranial; SC, spinal canal; Vol, volume.

Table 2: Pre- to post-lumbar puncture changes in ICP and CSF volume differences in the various compartments, amounts of CSF withdrawn, and the calculated effective CSF production rates

\begin{tabular}{|c|c|c|c|c|c|c|c|}
\hline & $\begin{array}{l}\text { Closing-Opening } \\
\text { Pressure }\left(\mathrm{cm} \mathrm{H}_{2} \mathrm{O}\right)\end{array}$ & $\begin{array}{c}\text { EVC CSF } \\
\text { Vol Change } \\
\text { (mL) }\end{array}$ & $\begin{array}{l}\text { Ventricular } \\
\text { CSF Vol } \\
\text { Change (mL) }\end{array}$ & $\begin{array}{c}\text { SC CSF } \\
\text { Vol Change } \\
\text { (mL) }\end{array}$ & $\begin{array}{c}\text { Total CSF } \\
\text { Vol Change } \\
\text { (mL) }\end{array}$ & $\begin{array}{l}\text { Amount of } \\
\text { CSF Collected } \\
(\mathrm{mL})\end{array}$ & $\begin{array}{c}\text { Effective } \\
\text { CSF Production } \\
\text { Rate (mL/min) }\end{array}$ \\
\hline \multicolumn{8}{|c|}{ Subject No. } \\
\hline 1 & NA & -1.6 & 0.0 & -5.3 & -6.9 & -16.0 & 0.25 \\
\hline 2 & -26 & -2.0 & -0.1 & -6.2 & -8.2 & -16.0 & 0.24 \\
\hline 3 & -3 & -3.6 & -0.1 & -6.0 & -9.6 & -14.0 & $\mathrm{NA}^{\mathrm{a}}$ \\
\hline 4 & -15 & 0.7 & 0.2 & -3.3 & -2.5 & -14.0 & 0.65 \\
\hline 5 & -16 & 2.0 & 0.1 & -12.7 & -10.5 & -21.0 & 0.43 \\
\hline 6 & -20 & -1.6 & -0.6 & -8.1 & -10.3 & -20.0 & 0.63 \\
\hline 7 & -12 & -1.0 & -0.2 & -2.7 & -3.9 & -8.5 & 0.24 \\
\hline 8 & -28 & 0.8 & 0.1 & -9.1 & -8.2 & -17.0 & 0.40 \\
\hline Mean & $-17 \pm 8.6$ & $-0.8 \pm 1.8$ & $-0.1 \pm 0.2$ & $-6.7 \pm 3.2$ & $-7.5 \pm 2.9$ & $-15.8 \pm 3.9$ & $0.41 \pm 0.18$ \\
\hline$P$ value & $.002^{b}$ & .24 & .45 & $.0007^{\mathrm{b}}$ & $.0002^{b}$ & & \\
\hline
\end{tabular}

Note:-ICP indicates intracranial pressure; NA, not available; EVC, extraventricular cranial; SC, spinal canal; Vol, volume.

${ }^{a}$ Effective CSF production rate for subject 3 was not calculated because the lumbar puncture time was not available.

b Significant.
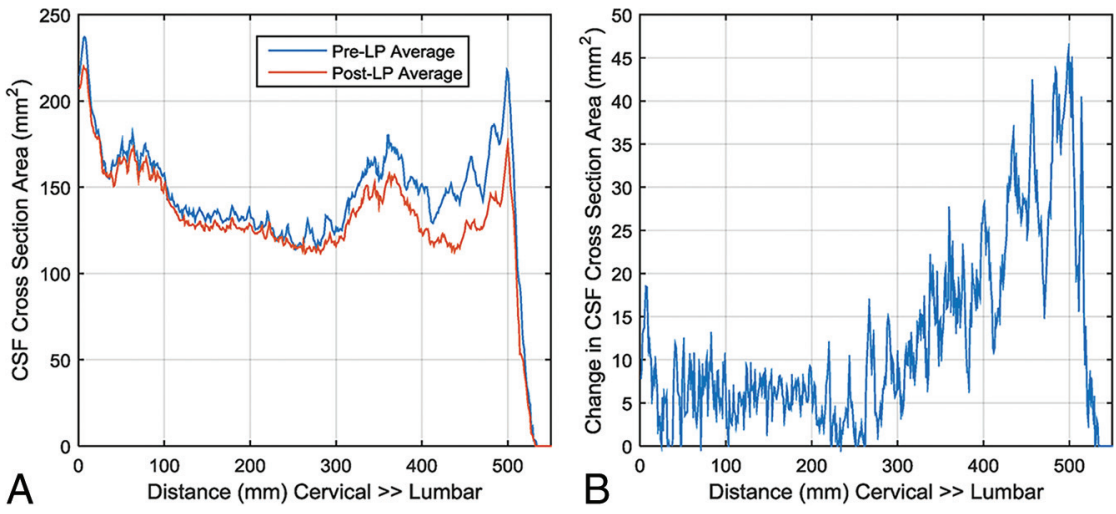

FIG 4. Average CSF cross-sectional area before and after lumbar puncture $(A)$ and average change in CSF cross-sectional area following CSF withdrawal with respect to the distance from the foramen magnum to the caudal end of the thecal sac $(B)$.

formed between the LP and MR imaging, we calculated a mean effective net CSF formation rate of $0.41 \pm 0.18 \mathrm{~mL} / \mathrm{min}$. The calculated net CSF production rates for each subject are listed in Table 2.

\section{DISCUSSION}

The method for segmentation of the spinal CSF spaces and spinal cord demonstrated highly reproducible measurements with a measurement variability of around $1 \%$ for both the spinal CSF and cord volumes. This method, in combination with existing methods for segmentation of the cranial CSF and brain tissue volumes, provides means for determining normative and altered spinal CSF volumes in the healthy and disease states, respectively. The improved performance of the method is attributed to the iterative approach to overcome biases due to image nonuniformities associated with large anatomic coverage.

The mean spinal CSF volume measured in a cohort of patients with IIH of $77.5 \pm 8.4 \mathrm{~mL}$ is comparable with a previously reported value of $76 \pm 23 \mathrm{~mL}$ measured in a healthy cohort of mixed sex ( 5 men/7 women) and a wide age range (25-84 years). ${ }^{13}$ The much wider SD measured in that study is likely due to the mixed sex and wider age range. $\mathrm{A}$ slightly larger spinal CSF volume of $81 \pm 13 \mathrm{~mL}$ was reported in 22 healthy elderly subjects ( 11 men/11 women) $(70 \pm 4$ years $)$, but most interesting, the cord volume of $20 \pm 3 \mathrm{~mL}$ measured manually in that study ${ }^{12}$ is similar to the value of $21.0 \pm 2.0 \mathrm{~mL}$ measured in the current cohort.

The automated measurement of the spinal CSF volumes was applied to investigate interindividual variability in different compartments and the redistribution of the CSF volume in the craniospinal system following removal via lumbar puncture. Inter- 

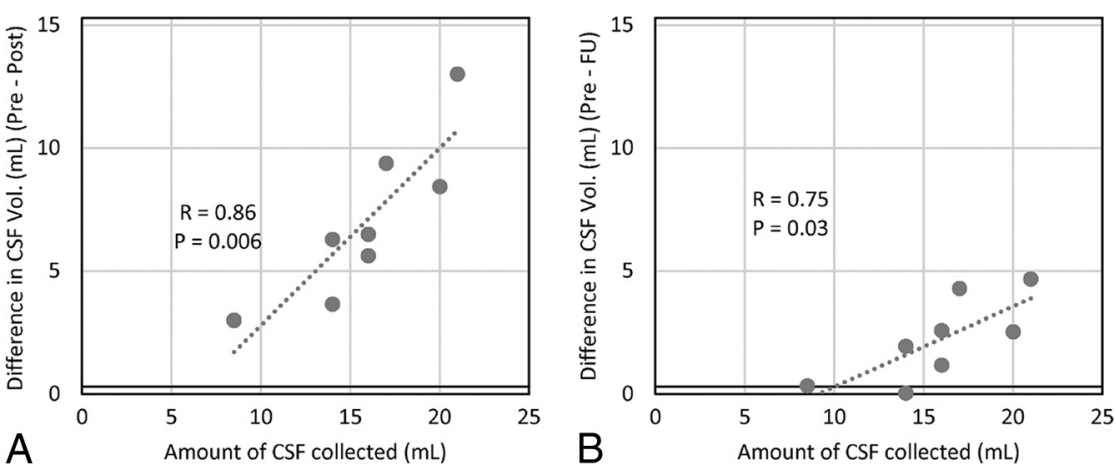

FIG 5. The relationship between the CSF volume withdrawn during lumbar puncture and CSF volume change in the spinal canal between the pre- and post-lumbar puncture scan $(A)$ and the pre- and the 2-week follow-up scan $(B)$ as measured by the proposed method.

estingly, the interindividual variability in CSF volumes in the IIH cohort was largest in the ventricles and smallest in the spinal canal. Automated whole CNS segmentation provides the means to determine the role of the spinal CSF volume in various diseases.

Craniospinal redistribution of the CSF volumes following withdrawal of CSF has not been reported previously. A small reduction of $1.4 \%$ in ventricular volume was reported following high-volume CSF withdrawal in elderly patients with normal pressure hydrocephalus. ${ }^{2}$ In contrast, in our study of younger patients with $\mathrm{IIH}$, the ventricular volume was unchanged following CSF withdrawal. This finding can be partly attributed to the much smaller ventricular volume $(16.2$ versus $160 \mathrm{~mL})$ and the smaller amount of CSF removed (15.8 versus $35 \mathrm{~mL}$ ) in the current study.

This study provides important insight into the pathophysiology of IIH. The reduction in CSF volume following lumbar puncture was predominantly from the spinal compartment, with nearly unchanged CSF volume in the cranial compartment. This finding implies that the drop in opening pressure following LP in $\mathrm{IIH}$ while the patients are in the supine posture is primarily due to an increase in the spinal canal compliance and less due to changes in the cranial compartment. The increased spinal canal compliance measured in the supine posture has implications for the upright posture because it allows larger amounts of CSF to shift from the cranium into the spinal canal following a change from a supine to an upright posture. This result, in turn, leads to a larger decrease in intracranial pressure in the upright posture. This observation that CSF volume reduction following LP is primarily from the spinal canal is consistent with a previous report that obesity-related IIH is associated with reduced spinal canal compliance. ${ }^{17}$ It seems that the therapeutic effect of CSF withdrawal by LP in IIH is achieved by improving the impaired spinal canal compliance.

The reduction in the spinal CSF volume was found to be localized primarily to the lumbar region. This finding is consistent with previous findings that regional compliance varies along the spinal canal, with the lumbar region providing the largest contribution to the overall spinal compliance. ${ }^{18}$ This is also consistent with radionuclide cisternography studies in which tracer injected into the lumbar region demonstrated slow dispersion along the spinal canal and the tracer distribution after 30 minutes was still localized to the lower lumbar region, ${ }^{19}$ similar to the pattern of volume difference shown in Fig $4 B$ in our study. The possibility of changing the spinal canal compliance locally by CSF withdrawal demonstrated in this study has important implications for the delivery of spinal anesthesia because the magnitude of the compliance at the lumbar region strongly influences the rate of dispersion of injected material in the CSF spaces.

Measurements of the entire CSF volume before and after CSF withdrawal in conjunction with other approaches for measurement of CSF formation rates ${ }^{20}$ are potentially useful for understanding the impact of treatment on CSF homeostasis in IIH. The imaging-based measurements of reduction in the craniospinal CSF volumes were consistently smaller than the withdrawn amounts. This outcome is not likely due to a measurement error, which would have resulted in both positive and negative changes. The most likely explanation for the smaller measured differences is a net CSF formation that occurred during nearly half an hour between the LP and the post-LP MR imaging. The effective increase in the net rate of CSF formation is well-explained by a lower CSF absorption rate caused by the lower intracranial pressure. ${ }^{21}$ An effective net formation rate was derived on the basis of the differences between the withdrawn and measured CSF volumes. The estimated mean effective formation rate of $0.41 \pm 0.18 \mathrm{~mL} / \mathrm{min}$ is larger than the normative value of $0.30 \pm 0.14 \mathrm{~mL} / \mathrm{min}$ reported in healthy subjects ${ }^{20}$ but similar to the CSF formation rate of $0.44 \pm 0.28 \mathrm{~mL} /$ min previously reported in 11 female patients with $\mathrm{IIH}$ and obesity. ${ }^{22}$ Another interesting finding is that the measured pre- to post-lumbar puncture differences in the CSF volumes were strongly correlated with the amount withdrawn, even at the 2-week follow-up MR imaging; this finding is consistent with reports in the literature of improved symptoms for 2 weeks following lumbar puncture. ${ }^{23}$

Limitations of this study are the relatively small number of patients, with one patient not meeting the modified Dandy criteria for IIH due to normal opening pressure. Another possible limitation is the lack of comparison with manually segmented CSF spaces. On the other hand, manual segmentations are not only time-consuming but also highly variable; thus, they may not be a reliable criterion standard. The use of a phantom, repeat measurements in the same subjects, and measurement before and after lumbar withdrawals provided an alternative approach for assessment of the reliability of the method. Finally, performing the CSF volume measurements in only the supine posture is another limitation of the study.

\section{CONCLUSIONS}

An automated method for delineation of the spinal CSF spaces has been developed and applied to study the effect of lumbar CSF withdrawal on the craniospinal CSF redistribution in IIH. The study reveals that the drop in the opening pressure following CSF withdrawal is related to an increase in the spinal canal compliance caused by reduction in spinal CSF volume localized to the lumbar region. The study demonstrates the importance of the spinal com- 
partment in intracranial pressure regulation and the benefit of automated craniospinal CSF volumetry to further elucidate the pathophysiology of CSF-related diseases.

Disclosures: Noam Alperin—UNRELATED: Board Membership: Alperin Noninvasive Diagnostics. Byron L. Lam—RELATED: Grant: North American Neuro-Ophthalmology Society pilot grant.* *Money paid to the institution.

\section{REFERENCES}

1. Silverberg GD, Heit G, Huhn S, et al. The cerebrospinal fluid production rate is reduced in dementia of the Alzheimer's type. Neurology 2001;57:1763-66 CrossRef Medline

2. Singer OC, Melber J, Hattingen E, et al. MR volumetric changes after diagnostic CSF removal in normal pressure hydrocephalus. J Neurology 2012;259:2440-46 CrossRef Medline

3. Alperin N, Ranganathan S, Bagci AM, et al. MRI evidence of impaired CSF homeostasis in obesity-associated idiopathic intracranial hypertension. AJNR Am J Neuroradiol 2013;34:29-34 CrossRef Medline

4. Onuki E, Higuchi H, Takagi S, et al. Gestation-related reduction in lumbar cerebrospinal fluid volume and dural sac surface area. Anesth Analg 2010;110:148-53 CrossRef Medline

5. Alperin N, Lee SH, Sivaramakrishnan A, et al. Quantifying the effect of posture on intracranial physiology in humans by MRI flow studies. J Magn Reson Imaging 2005;22:591-96 CrossRef Medline

6. Lee RR, Abraham RA, Quinn CB. Dynamic physiologic changes in lumbar CSF volume quantitatively measured by three-dimensional fast spin-echo MRI. Spine (Phila Pa 1976) 2001;26:1172-78 CrossRef Medline

7. Higuchi H, Adachi Y, Kazama T. The influence of lumbosacral cerebrospinal fluid volume on extent and duration of hyperbaric bupivacaine spinal anesthesia: a comparison between seated and lateral decubitus injection positions. Anesth Analg 2005;101:555-60 CrossRef Medline

8. Rashid W, Davies GR, Chard DT, et al. Increasing cord atrophy in early relapsing-remitting multiple sclerosis: a 3 year study. J Neurol Neurosurg Psychiatry 2006;77:51-55 CrossRef Medline

9. Fischl B, Salat DH, Busa E, et al. Whole brain segmentation: automated labeling of neuroanatomical structures in the human brain. Neuron 2002;33:341-55 CrossRef Medline

10. Ashburner J, Friston KJ. Unified segmentation. Neuroimage 2005;26: 839-51 CrossRef Medline

11. Hogan QH, Prost R, Kulier A, et al. Magnetic resonance imaging of cerebrospinal fluid volume and the influence of body habitus and abdominal pressure. Anesthesiology 1996;84:1341-49 CrossRef Medline

12. Edsbagge M, Starck G, Zetterberg H, et al. Spinal cerebrospinal fluid volume in healthy elderly individuals. Clin Anat 2011;24:733-40 CrossRef Medline

13. Lebret A, Hodel J, Rahmouni A, et al. Cerebrospinal fluid volume analysis for hydrocephalus diagnosis and clinical research. Comput Med Imaging Graph 2013;37:224-33 CrossRef Medline

14. Horsfield MA, Sala S, Neema M, et al. Rapid semi-automatic segmentation of the spinal cord from magnetic resonance images: application in multiple sclerosis. Neuroimage 2010;50:446-55 CrossRef Medline

15. Smith SM. Fast robust automated brain extraction. Hum Brain Mapp 2002;17:143-55 CrossRef Medline

16. Chan TF, Vese LA. Active contours without edges. IEEE Trans Image Process 2001;10:266-77 CrossRef Medline

17. Tain RW, Bagci AM, Lam BL, et al. Determination of cranio-spinal canal compliance distribution by MRI: methodology and early application in idiopathic intracranial hypertension. J Magn Reson Imaging 2011;34:1397-404 CrossRef Medline

18. Yallapragada N, Alperin N. Characterization of spinal canal hydrodynamics and compliance using bond graph technique and CSF flow measurements by MRI. In: Proceedings of the Scientific Meeting and Exhibition of the International Society for Magnetic Resonance in Medicine, Kyoto, Japan. May 15-21, 2004:2658

19. Greitz D, Hannerz J A proposed model of cerebrospinal fluid circulation: observations with radionuclide cisternography. AJNR Am J Neuroradiol 1996;17:431-38 Medline

20. Huang TY, Chung HW, Chen MY, et al. Supratentorial cerebrospinal fluid production rate in healthy adults: quantification with two-dimensional cine phase-contrast MR imaging with high temporal and spatial resolution. Radiology 2004;233:603-08 CrossRef Medline

21. Cutler RW, Page L, Galicich J, et al. Formation and absorption of cerebrospinal fluid in man. Brain 1968;91:707-20 CrossRef Medline

22. Alperin N, Lam BL, Tain RW, et al. Evidence for altered spinal canal compliance and cerebral venous drainage in untreated idiopathic intracranial hypertension. Acta Neurochir Suppl 2012;114:201-05 CrossRef Medline

23. Scoffings DJ, Pickard JD, Higgins JN. Resolution of transverse sinus stenoses immediately after CSF withdrawal in idiopathic intracranial hypertension. J Neurol Neurosurg Psychiatry 2007;78:911-12 CrossRef Medline 